\title{
DESARROLLO DE UN SISTEMA DE RECICLAJE DE AGUAS RESIDUALES TEXTILES COLOREADAS MEDIANTE LA UTILIZACIÓN DE UN FOTOREACTOR SOLAR
}

\author{
Andrés Zaconeta Piva y Ramiro Escalera Vásquez
}

\section{RESUMEN}

Se ha desarrollado un sistema de reciclaje de aguas residuales provenientes de la etapa de adición de colorantes orgánicos en el proceso de teñido de jeans, a nivel de laboratorio, que consiste en dos procesos: la foto-degradación por el método foto-Fenton del color y de la materia orgánica, utilizando un foto-reactor solar tubular de sección semicircular de un solo eje y la precipitación/filtración de hierro remanente en las aguas foto-degradadas.

El colector-concentrador solar, que posee una capacidad de concentración de radiación UV-A de 2,88 soles, fue construido reciclando materiales desechados: tubos de vidrio proveniente de lámparas de Ne y tubos de desagüe sanitario de 6" (PVC), recubierto por láminas de aluminio.

Se realizaron pruebas de optimización del proceso de foto-degradación mediante un modelo estadístico factorial de multiniveles, dando como resultado concentraciones óptimas de $\mathrm{Fe}^{2+} 35 \mathrm{mgL}^{-1}$ y de $\mathrm{H}_{2} \mathrm{O}_{2} 1400 \mathrm{mgL}$, $\mathrm{pH}_{\text {óptimo }}$ entre 2,35 a 2,40 e intensidad de radiación solar UV-A integral incidente entre 50 y $70 \mathrm{Wm}^{-2}$ (radiación efectiva que recibe la solución entre 144 y $202 \mathrm{Wm}^{-2}$ ).

Aplicando las condiciones óptimas a soluciones de tinte (Negro, Azul Marino y Rojo Escarlata) preparadas en laboratorio se llegaron a porcentajes de remoción del $81 \%, 98 \%$ y $93 \%$ respectivamente. En cambio, en la fotodegradación de los licores reales de la industria se llegó a un porcentaje de remoción del $77 \%$ y una disminución de la DQO de $92 \%$, reduciendo drásticamente el poder contaminante de este efluente.

Se determinaron experimentalmente las constantes cinéticas de pseudo-primer orden y tiempos medios de proceso dando los siguientes resultados en las soluciones de tinte: Negro $\mathrm{k}_{\mathrm{app}}$ 0,0336 min $^{-1}$ y $_{1 / 2} 20,63$ min, Azul Marino $\mathrm{k}_{\mathrm{app}}$ $0,0568 \mathrm{~min}^{-1}$ y $_{1 / 2} 12,20 \mathrm{~min}$ y para el Rojo Escarlata $\mathrm{k}_{\text {app }} 0,0164 \mathrm{~min}^{-1}$ y $_{1 / 2} 42,27 \mathrm{~min}$. Para el licor se obtuvo: degradación del tinte $\mathrm{k}_{\mathrm{app}} 0,0356 \mathrm{~min}^{-1} \mathrm{y}$ el $\mathrm{t}_{1 / 2}$ es de 19,47 min y para la disminución de la DQO $\mathrm{k}_{\text {app }} 0,0196 \mathrm{~min}^{-1} \mathrm{y}$ $\mathrm{t}_{1 / 2} 35,4 \mathrm{~min}$. Se trataron los efluentes foto-degradados mediante la precipitación del hierro residual con soda caustica comercial $\left(0,75 \mathrm{gL}^{-1}\right)$ y una filtración hasta llegar a una concentración residual de hierro de 4,36 mgL ${ }^{-1}$. Pruebas de reutilización de los licores tratados en la etapa de adición de colorantes, a escala de laboratorio, demostraron que no existen diferencias en la calidad de los tejidos teñidos. Con estos antecedentes se puede concluir que el sistema de tratamiento y reciclaje propuesto es viable técnicamente.

Palabras Clave: Foto-Degradación, Tintes Industriales, Foto-Fenton, Radiación UV-A Solar. 